In press at Meta-Psychology

[4th February 2022]

\title{
A Theory of Ethics to Guide Researchers' Formulation of Psychological Investigative Interviewing Methods
}

\author{
Author Note \\ David A. Neequaye, Department of Psychology, University of Gothenburg. \\ I thank Lorraine Hope and Erik Mac Giolla for providing immensely useful comments \\ on earlier versions of this work. I am fully and solely responsible for any errors in this article. \\ Correspondence to: David A. Neequaye, Department of Psychology, University of
} Gothenburg. Box 500, 40530 Gothenburg, Sweden; Email: david.neequaye@ psy.gu.se

Data Availability Statement: This work contains no empirical data. 


\begin{abstract}
This article examines ethical considerations relevant to the formulation of psychological investigative interviewing techniques or methods. Psychology researchers are now devoting much attention to improving the efficacy of eliciting information in investigative interviews. Stakeholders agree that interviewing methods must be ethical. However, there is a less concerted effort at systematically delineating ethical considerations to guide the creation of interviewing methods derived from scientific psychological principles. The disclosures interviewees make may put them at considerable risk, and it is not always possible to determine beforehand whether placing interviewees under such risks is warranted. Thus, I argue that research psychologists aiming to contribute ethical methods in this context should ensure that those methods abide by a standard that actively protects interviewees against unjustified risks. Interviewing techniques should provide interviewees, particularly vulnerable ones, with enough agency to freely determine what to disclose. Researchers should explicitly indicate the boundary conditions of a method if it cannot achieve this standard. Journal editors and reviewers should request such discussions. The suggested standard tasks research psychologists to be circumspect about recommending psychological techniques without fully addressing the ethical boundaries of those methods in their publications. I explain the proposed ethical standard's necessity and discuss how it can be applied.
\end{abstract}

Keywords: disclosure; ethical investigative interviewing; human intelligence source; psychological manipulation; suspect; witness 


\section{A Theory of Ethics to Guide Researchers' Formulation of Psychological Investigative Interviewing Methods}

This article discusses ethical considerations relevant to the formulation of psychological investigative interviewing techniques or methods. Such techniques are means of asking people questions in investigative interviews. In those interviews, interviewers question interviewees to potentially elicit information pertinent to perceived local/national or international security concerns or interests a governing entity may have. I use the word, perceived, deliberately in this definition of investigative interviewing. Different governing entities may have different views on whether an investigation is a security issue or whether an interest is legitimate. Another term, interrogation, has a similar meaning as investigative interviewing (see, e.g., Hartwig et al., 2014). However, some stakeholders associate interrogation with questioning methods aimed at confirming a preconceived notion rather than eliciting information (Rachlew, 2017; Williamson, 1993). Therefore, I adopt the term investigative interviewing. The term is arguably a more intuitive designator of the majority of social interactions wherein the objective is to elicit truthful information in an investigation or interview.

Before proceeding, it is critical to preempt any later confusion by noting relevant topics that are not the current article's focus. This examination does not discuss the ethics of interviews psychologists conduct, such as psychological evaluations in the health sector, for employers, and other organizations. Additionally, the article does not delve into how psychologists should personally comport themselves when directly performing consultations in a professional capacity. The APA Ethical Principles of Psychologists and Code of Conduct addresses these important issues (APA, 2002), which are not the focus of the present discussion. 
The article centers on investigative interviewing pertaining to national/international security concerns and interests - and research psychologists contributing ethical methods to that enterprise. Research psychologists may serve as consultants, advising directly on actual investigative interviews, and it is generally recommended that such consultations follow the APA ethical guidelines. It is worth repeating here that this article does not delve into how research psychologists should personally comport themselves during professional consultations. Previous examinations have addressed these essential issues (see, e.g., APA, 2002; Porter et al., 2016). Moreover, this work does not address how security personnel, for example, the police, should behave when conducting investigative interviews - or the ethicallegal standards thereof (e.g., the recording of suspect and witness interviews). Other research has examined such essential issues (see, e.g., Clarke \& Milne, 2001; Newton, 1998; Snook et al., 2020).

This article focuses on the burgeoning research field where research psychologists contribute somewhat indirectly by developing and recommending psychological interviewing techniques to be used by other practitioners, specifically, law enforcement and intelligence interviewers. Many existing scientific publications recommend such psychological interviewing techniques (see, Vrij et al., 2017; Vrij \& Granhag, 2014 for overviews). The ethics of these methods published in scientific journals remain underexamined. Existing ethics codes are either underspecified for investigative interviewing (e.g., APA 2002) or typically speak to how researchers or psychologists should personally comport themselves (e.g., Porter et al., 2016). This article explores and specifies ethical considerations relevant to indirect contributions to investigative interviewing that feature in psychology journal articles.

\section{Researchers' Current Focus on Developing Psychological Interviewing Techniques}

Various events in recent history have sparked a general interest in investigative interviewing. For example, (a) the discovery that the Central Intelligence Agency (United 
States) used undeniably abusive questioning methods at Guantanamo Bay and Abu Ghraib (Cohen, 2005); (b) the revelations that law enforcement personnel routinely employ dubious techniques that elicit false confessions to crimes (Kassin, 2017); (c) the missed opportunities to obtain information that could have helped prevent security breaches worldwide (Soufan, 2011). Psychology researchers are now devoting much attention to improving the efficacy of eliciting information in investigative interviews (Meissner, 2021; Vrij et al., 2017). The majority of research focused on developing interviewing techniques draws on psychological principles that facilitate disclosure. Researchers and practitioners agree that interviewing methods must be ethical (Alison \& Alison, 2017; Hartwig et al., 2014; Vrij et al., 2017). However, there is a less concerted effort at systematically delineating ethical considerations relevant to the creation of interviewing methods derived from scientific psychological principles.

Two seminal works have considered this topic previously. Skerker (2010) extensively discusses the morality of investigative interviewing. Hartwig et al. (2016) reviewed extant psychological interviewing methods, at the time, and analyzed their moral implications. The present work draws on Skerker (2010) and Hartwig et al. (2016), and when necessary, I will describe the relevant aspects. However, this work is not a commentary on those publications. The current article takes a different approach and examines the ethics of investigative interviewing in ways that address existing interviewing methods and those that may be developed in the future. This work aims to contribute to the discussion by calling on the field to now consider a more forward-looking approach. I will argue that interviewing methods should provide interviewees, particularly vulnerable ones, with enough agency to freely determine what to disclose. As such, researchers should explicitly indicate the boundary conditions of a technique if it cannot achieve this standard. The proposed ethical standard may 
assist in regulating researchers' creation and publication of psychological interviewing techniques.

The proposed standard purposely focuses on the publications of research psychologists for pragmatic reasons. Guidelines aimed directly at practicing investigative interviewers may be ineffective since practitioners are generally under no obligation to abide by an ethical standard the academic literature posits - unless the relevant authorities ratify the standard. Such ratification may comprise an arduous and lengthy bureaucratic process, decelerating the goals at hand.

Nonetheless, practicing interviewers may draw on the recommendations of research publications, and they are encouraged to do so (Fallon, 2014). Suppose a publication indicates that an interviewing technique leads people to disclose information. In that case, a practitioner may implement the technique in an actual interview. This possibility offers a pragmatic way for the academic literature to proactively contribute to practitioners using ethical methods. We must ensure that the methods researchers develop and recommend via their publications are ethical. The editorial process of scientific publishing is an opportune avenue to assure that researchers primarily disseminate ethical interviewing methods. Importantly, this approach could preempt possibilities for the scientific literature to sustain or produce ethically problematic techniques that practitioners might adopt. However, there is little specification when it comes to standards by which to determine the ethical nature of interviewing methods researchers publish.

Later, I will elaborate on the details of the proposed ethical standard; now, I will explain its pragmatic necessity. The APA ethics code (APA, 2002) offers principles to govern the psychology profession; two are relevant to the publication of investigative interviewing methods in psychology journals. Principle A: the beneficence and nonmaleficence principle charges members of the psychology profession to ensure that they do no harm. In this view, 
we must strive to safeguard the welfare of those whom our work may affect. Principle E calls for respecting people's rights and dignity. The work of psychology should not infringe on individuals' rights to privacy, confidentiality, and self-determination. It is incumbent upon research psychologists to ensure that their publications align with the relevant ethics codes. However, the APA ethics code is designed to be applicable across the organization's many ( 54) divisions; the principles therein are purposely aspirational. The respective divisions and fields of psychology are encouraged to create enforceable standards that put the APA ethics principles into action (Behnke, 2006). The standard this article proposes is an attempt to provide such an enforceable standard applicable to the development and recommendation of investigative interviewing methods via scientific publication. Put simply, the standard is an effort to provide a metric to assure that published interviewing techniques align with the beneficence and nonmaleficence plus the respect for rights and dignity principles.

To my knowledge, a compendium of generally applicable ethics principles does not exist when it comes to psychological interviewing methods. The current state of the literature is not exactly a shortcoming but an inevitable result of moral and legal entanglements commonly associated with investigative interviewing (see, e.g., Sukumar et al., 2016). Moreover, there are varied legal jurisdictions and cultural contexts worldwide. Broadly examining legal nuances simultaneously with the morality of psychological techniques will be close to unmanageable. Thus, this work will focus on moral issues that generally arise when people are subjected to psychological techniques in investigative interviews. The analysis will not delve into the specific laws of any context. Also, this article does not necessarily provide a complete theory. The goal is to offer a general proposal to commence open discussions on the topic.

I have structured the remainder of this article as follows. First, the work discusses the moral challenges and legitimacy of investigative interviewing. Next, I describe the categories 
of people that typically feature in interviews and the risks interviews pose to them. The article then explores how research psychologists may structure interviewing methods they develop to navigate such risks ethically. Finally, I explore the ethical nature of the Scharff technique - an interviewing method that features in the published literature. That analysis provides an example of how one may examine the ethics of an interviewing technique.

\section{Moral Challenges of Investigative Interviewing}

Investigative interviews contain a moral conundrum: to what extent is it permissible to (sometimes) compel people to submit to questioning about whatever topic a governing entity deems fit? Surely one is entitled to keep what they know a secret if one wishes? Controlling the information one wants to be open or secret is the essence of human autonomy - that is, one's ability to determine their identity, intentions, possessions, and actions (Bok, 1983). Previous works, namely, Hartwig et al. (2016) and Skerker (2010) have addressed this general problem investigative interviewing raises. I will draw on the relevant aspects of those works to reiterate the legitimacy of investigative interviewing because the discussion is a useful reminder, and it sets the stage for the remainder of this work.

Bok (1983) argues that one cannot automatically approve or disapprove of secrecy. One must examine the moral arguments for every occasion where the justifiability of secrecy is under contention (Bok, 1983). Let us now address whether investigative interviewing, which often comprises probing others' secrets, is a justifiable enterprise. Liberal democracy is presently the most popular form of national and international government (e.g., Mukand \& Rodrik, 2020). In this system of governance, founded on deontological ethics, a significant aspect of exercising one's rights is the freedom to enjoy autonomy without interference (Hartwig et al., 2016). There is a general understanding that people are morally equal; Skerker (2010) explains this phenomenon in detail, and the remainder of this paragraph provides a summary. Mutual respect for one another's rights upholds moral equality. One can fully enjoy 
one's rights if they do not impede another's rights (Skerker, 2010). For example, a person is free to own a house provided she purchases it using her resources, not stealing another's house. Illegitimate means of exercising one's rights is a rights violation. The violator consequently forfeits the expectation that others will respect her rights. Hence, it is permissible to inhibit such violations but only to the extent that the restraint restores the status quo-moral equality (Skerker, 2010).

Typically, in liberal democracies, the state or the legitimate governing entity is responsible for ensuring moral equality by protecting the interests of the governed. Accordingly, governing entities usually have a monopoly on coercion. They can, therefore, compel the governed to attend investigative interviews if there is cause to believe a deviation in moral equality has occurred. As such, the interview may support efforts to restore the status quo. For instance, a murder suspect may be detained and questioned about their whereabouts when the crime happened. Ordinarily, detaining, and asking anyone to share personal details compromises their autonomy, which is a rights violation. However, Hartwig et al. (2016) note that a warranted temporary restriction of a person's rights, as in the example of this murder suspect, is not necessarily a violation but a rights infringement. An infringement, in this case probing the secrets of a suspected murderer, is not inherently wrong. Remember that governing entities in liberal democracies are responsible for safeguarding moral equality, which allows the mandate to compel.

Nonetheless, such rights infringements must not exceed the amount of compelling a governing entity needs to restore the status quo (Skerker, 2010). The governed have the right to procedural fairness or natural justice (Bayles, 2012). But investigative interviewing is fraught with epistemic limitations. It is impossible always to know whether subjecting a person to an interview is justified in the first place, a significant part of interviewing aims to determine if the interview is appropriate (Hartwig et al., 2016). Suspects undergo questioning as part of 
establishing whether they are culprits - they might well be innocent. An interviewer might have to ask an informant probing questions before fully determining whether the probe was necessary for understanding some investigation of interest. These epistemic limitations make it challenging to establish the extent to which chosen interviewing methods overly infringe on an interviewee's autonomy - and rise to the level of a rights violation. That is to say, investigative interviews are highly morally risky (Hartwig et al., 2016). However, interviews are a necessary aspect of assuring moral equality. Thus, it is critical to equip stakeholders to better anticipate such moral risks. That knowledge could be a useful crutch to navigate the formulation of interviewing methods ethically.

\section{People Subjected to Interviews}

A central discussion point regarding the moral risks of investigative interviewing is the injuries interviewing methods pose or could pose to interviewees or people subjected to interviews. For example, the examination by Hartwig et al. (2016) classified the existing psychological interviewing techniques into themes and analyzed their potential moral hazards; next follows a summary. One theme comprised interviewing techniques that seek to confirm preconceived notions of guilt. Those methods implement coercive and deceptive practices to elicit confessions; examples include deceptively minimizing or maximizing the consequences of crimes to force suspects to confess at any cost (Inbau et al., 2001). Confession-based techniques have been shown to reliably elicit false confessions (see Kassin, 2017). Moreover, such methods damage the integrity of interviewers and the institutions under which they serve (Hartwig et al., 2016).

The other theme consists of interviewing methods that actively avoid confirming preconceived notions. The PEACE model is an example of a framework under the informationgathering approach (see Clarke \& Milne, 2001 for an overview). PEACE is an abbreviation denoting five stages of the interviewing process_-Planning and Preparation; Engaging and 
explaining; asking an interviewees' Account of events; Closure; and Evaluation. The PEACE model offers the interviewee maximum opportunities to provide a thorough account in response to an interviewer's inquiries. Other techniques advocate asking questions in a manner that elicits differences between liars and truth tellers (Granhag \& Hartwig, 2014; Vrij, 2018). Some methods also employ subtle elicitation tactics that lead interviewees to disclose information without realizing they have provided new information (Oleszkiewicz et al., 2014). In all, the techniques under the information-gathering theme equip interviewers with tactics and strategies to gather information about a topic of interest. Hartwig et al. (2016) note that the information-gathering theme provides a better ethical view of investigative interviewing. It focuses on treating interviewees fairly and respecting their rights - unlike confession-based methods.

I have chosen a different way of approaching the topic by first categorizing interviewees to provide a generic classification system. This entry point offers a novel approach different from Hartwig et al. (2016) and is useful because it allows a more tractable and forward-looking discussion than classifying interviewing techniques. We cannot anticipate all the methods that might be developed in the future. Hence, a classification of extant interviewing techniques is likely to become limited as the field develops new methods. Classifying interviewees affords a forward-looking analysis and offers more longevity. Such a categorization allows one to examine whether any existing or upcoming interviewing method may pose injuries to the class of interviewees from which the technique aims to elicit information. Generically classifying interviewees better situates the field to examine the moral implications of current and future interviewing methods. Additionally, the shift in analysis, highlighting interviewees' experiences, could spur discussions toward potential modifications existing techniques may need to enhance their ethical standards. 


\section{Types of Interviewees and the Risks for Worst-Case Outcomes}

Surveys of the literature reveal three general functions that can arguably characterize any interviewee ${ }^{1}$; a suspect, a witness, or a human intelligence (HUMINT) source (e.g., Vrij \& Granhag, 2014; Vrij et al., 2017). An individual is likely to fit at least one of these designations when questioned in an investigative interview at any time point. Hence, this classification system sets the stage for a forward-looking ethics analysis that offers more longevity. I will examine each interviewee category and the associated risk for worst-case outcomes in interviews.

\section{Suspects}

Suspects are individuals whom interviewers question because of reasonable grounds to believe, at least temporarily, that the person has committed a crime or some aspect of a crime. Typically, interviewers question suspects in a local/national law enforcement jurisdiction (e.g., Meissner et al., 2015). Some suspects can, however, be interviewed in an international law enforcement context (Glasius, 2006). International suspects usually feature in investigations sanctioned by intergovernmental organizations such as the International Criminal Court (ICC). Any act labeled a crime in a jurisdiction is unlawful by default. A governing entity can mete out punishment to anyone found guilty of a crime (Morrison, 2013; Tierney, 2009). If a suspect is convicted of a crime, penalties can range from a partial to a total loss of civil liberties. For example, those convicted can receive a fine or a prison sentence. What a suspect reveals during questioning could contribute to absolving or implicating them.

Risks. In the worst-case scenario, what a person discloses when questioned as a suspect could inadvertently cause them to lose some civil liberties or contribute to the loss.

\footnotetext{
${ }^{1}$ Possibly, some jurisdictions may call the categories by slightly different names. However, stakeholders are familiar with and frequently use these designators in the manner defined by the classification scheme. It is unlikely that the names used here will cause unnecessary ambiguity in the investigative interviewing literature.
} 


\section{Witnesses}

Like suspects, witnesses can feature in a local/national or an international law enforcement context. These individuals undergo interviews if they report having had some direct sensory experience of a crime under investigation or have been directly harmed. Ordinarily, these are cases where the person may have seen or heard aspects of a crime as a bystander (Read et al., 1995; Wells \& Olson, 2003) — or they may have been a victim of the crime (Spalek, 2016). The information a witness provides sheds light on the crime under investigation in various ways. Three are relevant here: (a) whatever a witness discloses may contribute to exculpating or incriminating a suspect; (b) or the information may lead someone to become a suspect. (c) In the first instance, a witness is not a suspect, and a witness may refuse to answer incriminating questions (Pieck, 1960). Nonetheless, if a witness unwittingly provides self-incriminating information, they may become a suspect in the investigation.

Risks. In the worst-case scenario, what a witness reveals may inadvertently cause another person or the witness themselves to become a suspect or ultimately lose some civil liberties (Wells \& Olson, 2003).

\section{Human Intelligence Sources}

HUMINT sources are questioned because they might possess information relevant to an investigation. A broad range of HUMINT investigations exist. Those investigations could be previous, ongoing, or possible future local/national or international crimes (Hartwig et al., 2014). The interest may also be a general security issue that is not exactly a crime (Burkett, 2013). For example, an investigation of known or ostensible threats posed by a local or foreign organization or a foreign government. Alternatively, the investigation could be gathering information to further an entity's interests (Ransom, 2013). For instance, a government seeking to gain insight into subjects that can inform foreign policy or foreign aid decisions. Unlike 
suspects, HUMINT sources are questioned primarily because of the information they may possess, not necessarily due to a belief that they have committed a crime.

There are a few distinctions between the HUMINT source and witness designations worth noting. Sometimes, the objective of an intelligence interview is to elicit information about a previous, ongoing, or imminent crime. Here, unlike witnesses, intelligence sources are those who may have obtained information indirectly and not necessarily through direct harm or sensory experience. For instance, another person could have provided the information a HUMINT source now holds. In this view, one could consider such indirect sources of information in criminal investigations to be intelligence sources, as they possess relevant information (Carter, 1990). Indeed, investigators may question other individuals to better understand aspects of an incident; for instance, cross-checking suspects' alibis or witness' statements using third party information. An example of such intelligence gathering could be interviewing various care-givers in a child sexual abuse case to shed light on the alleged abuse. Investigators may also ask independent experts about different aspects of a crime; for example, requesting an explanation of DNA evidence analysis. The goal could be to better understand, for instance, how the crime occurred.

Risks in Criminal Investigations. Despite the functional distinctions, the HUMINT source and witness designations have similar risks when an intelligence interview relates to a criminal investigation. A HUMINT source may provide information that contributes to implicating or absolving a suspect. Under certain circumstances, an intelligence interviewee could incriminate herself. Thus, the worst-case scenario here is a HUMINT source unwittingly revealing information - and those details implicate someone or her to become a suspect in a criminal investigation or eventually lose some civil liberties.

Risks in Non-Criminal Investigations. Other intelligence interviews entail eliciting information about general security issues such as criminal networks and foreign threats. 
Alternatively, the questioning can center on certain interests an entity may have (e.g., foreign policy decisions). These intelligence investigations are not necessarily alleged crimes, at least not until a governing entity launches a formal criminal investigation. Thus, here, an intelligence source may come by information directly, as a witness would, or the source could obtain it indirectly, as I have described earlier. Unlike witnesses who provide information about a specific (past) crime, intelligence sources here could undergo questioning about known or ostensible events. When the matter is a general security issue or an entity's interests, the worstcase eventuality for the HUMINT source is revealing details on a subject when one does not intend to.

\section{Caveats}

I must emphasize that the above categorizations derive from the immediate purpose or function an interviewee is serving during questioning. Thus, the classification scheme does not preclude an interviewee from switching roles during an ongoing or a subsequent interview. The point is - an interviewee assumes a designation depending on their current function, and those functions are subject to change.

\section{Navigating the Moral Risks of Investigative Interviewing}

The current article aims to improve the ethics of investigative interviewing techniques research psychologists publish. If so, why delve into risks to interviewees directly caused by practicing interviewers - not research psychologists? After all, jurisdictions have laws and guidelines to determine and prevent malpractice, at least in local and national law enforcement (e.g., College of policing, 2019). As I noted earlier, research psychologists recommend that practicing interviewers should implement interviewing methods published in the scientific literature. Often the recommendation comes with the claim that those techniques are ethical or elicit information effectively (see, e.g., Vrij et al., 2017). Suppose practitioners heed the recommendations of the published literature because of the presumed benefits. In that case, 
research psychologists may contribute indirectly to the risks interviewees face even though practitioners directly cause those risks. Therefore, it behooves research psychologists to be cognizant of the dangers they could inadvertently contribute to and preempt such possibilities. Importantly, research psychologists should strive to prevent possible misuse of techniques they publish.

Investigative interviewing is an inevitable aspect of assuring moral equality despite the risks involved. Thus, the critical question to now address is this: how should stakeholders ethically navigate these moral risks when developing interviewing methods? How should research psychologists design fail-safe techniques that inhibit interviewees from being excessively compelled in interviews? The following sections delve into these issues.

\section{Interviewees Should Decide Their Disclosures}

Actions that tend to result in unpleasant outcomes can be permissible if one consents to partaking (Hartwig et al., 2016; cf., Tadros, 2011). For example, pugilists consent to the possibility of concussions when they engage in prizefighting. In this view, the risks of investigative interviewing are not immoral by default. Hartwig et al. (2016) note that, sometimes, such outcomes are worthy of consent because, in liberal democracies, the governed expect governing entities to ensure moral equality. Citizens presume that governing entities will take action to keep them safe and protect their interests. However, epistemic limitations prevent knowing beforehand if an investigative interview is warranted. By extension, we also cannot know whether the potential worst-case scenario an interviewing method presents is worthy of consent. Interviewees must first disclose information for the worst-case scenario to arise. As a result, in liberal democracies, interviewees generally have the right to silence, even if they can be compelled to questioning in interviews. The right to silence allows the interviewee control over what information to be open or keep secret. This control assures that interviewees consent to the possible consequences of their disclosures beforehand. I use the 
phrase - possible consequences - deliberately because it is not always viable to foresee the exact outcomes of disclosures in interviews.

The right to determine one's disclosures may allow bad-faith actors to withhold information or provide misleading details to avoid deserved punishment. More importantly, however, such autonomy enables good-faith actors to provide all the information a governing entity may need toward ensuring moral equality (Seidmann \& Stein, 2000). These features do not necessarily advocate freeing the bad-faith actors. Instead, they uphold a primary aspect of moral equality — the protection of good faith actors (Bandes, 2009; Cassell, 2017). A critical parameter for what can be done to persons without compromising their rights is that no one should harm another without the other's consent (Nozick, 1974). In this vein, an interviewing method worthy of consent should inhibit the worst-case scenarios for good-faith actors in the class of interviewees from which it aims to elicit information.

Interviewing methods purposed to elicit information from suspects should make it near impossible for innocent suspects to inadvertently say anything that can cause or contribute to them losing civil liberties. The witness and HUMINT source designations in criminal investigations are similar. Techniques designed to elicit information from such interviewees should make it near impossible for an innocent person to say anything self-incriminating or unwittingly incriminate another innocent person.

HUMINT interviewing methods aimed at eliciting information about general security threats or an entity's interest should also protect interviewees' autonomy in deciding what to disclose. Because these intelligence interviews do not concern formal criminal investigations, interviewees here are not necessarily innocent or guilty. Consequently, such interviewees may be propositioned to submit to an interview and not compelled as a matter of course. To be consent-worthy, elicitation techniques purposed for such HUMINT sources should make it near impossible to say anything one has not formed a clear intention to share. The consequences of 
disclosure in these HUMINT contexts are highly unpredictable, unlike in criminal investigations where some rules (e.g., constitutions) regulate the potential outcomes of disclosure. As such, it should remain the source's prerogative to determine what to disclose; this provides reasonable assurance that the source has consented to the possible consequences of the disclosure.

\section{Two Principles for Ethical Interviewing Methods}

How should research psychologists formulate interviewing techniques that are worthy of consent? By what principles should those questioning methods strive to abide? This work offers two principles to set future discussions in motion. The following proposal aims to contribute to developing parameters to assess or guide the ethics of current and future psychological interviewing techniques.

A psychological interviewing method can achieve consent worthiness by ensuring the following. (a) An interviewee is maximally and instantaneously aware of an interviewer's inquiry or what the interviewer is asking; call this the inquiry-clarity principle. (b) An interviewee is maximally and instantaneously aware of the information they are choosing to disclose; call this the disclosure-awareness principle. These principles arguably give interviewees substantial agency to decide their disclosures and safeguard against disclosing information unwittingly. Suppose an interviewee has agency, that is, maximum and instant awareness of an interviewer's inquiry and forms a clear intention of an acceptable response, which she discloses. It is then conceivable that the interviewee has consented to the potential consequences of their disclosure. Agency allows the expectation that a person bears responsibility for their actions (Haggard \& Tsakiris, 2009; Moore, 2016; cf., Frith, 2014).

It is worth reiterating that the two principles are to be applied in serial order, the inquiry-clarity principle and then the disclosure-awareness principle. Both principles must be satisfied. Suppose that an interviewing technique falls short of making an interviewee aware 
of what an interviewer is asking. One cannot justify the consent-worthiness of that technique by claiming or demonstrating that the method makes interviewees aware of what they are choosing to disclose. Without inquiry-clarity, it is challenging, if not impossible, to ascertain a reasonably proximate cause of a disclosure. If the inquiry that elicited a disclosure is unknown, one cannot claim the unknown inquiry is consent-worthy, regardless of the interviewee's response. After satisfying the inquiry-clarity principle, the method must also allow the interviewee to choose their preferred response. Suppose a method elicits a legitimate response from an interviewee, but the interviewee does not realize they have offered such a response. In that case, the method falls short of the disclosure-awareness principle. Here, legitimate response means a response on the record that one can materially ascribe to the interviewee.

Proponents of a psychological interviewing technique must offer theoretical arguments or empirical evidence demonstrating the conditions under which the method satisfies the inquiry-clarity and disclosure-awareness principles. Such exposition will reveal the extent to which the method allows interviewees agency over their disclosures. Editors and reviewers of investigative interviewing research may draw on the principles offered here to request such discussions from authors. This requirement will encourage much-needed reflection about the ethics of interviewing methods.

The principles offer much-needed clarity about what constitutes a psychologically manipulative technique. Currently, the term psychological manipulation remains undefined in the investigative interviewing literature. Torture, physical coercion, and deceptive methods do not comport with the principles proposed here. Analysts condemn such practices (Meissner et al., 2015); they compromise interviewees' agency to freely determine what to disclose and essentially prevent one from providing accurate information. For example, deceptive interviewing techniques are prone to elicit false confessions (Kassin, 2017; Kassin \& Kiechel, 1996). Hartwig et al. (2016) address the immorality of these dubious methods; they note that 
such techniques undermine society's trust in public institutions and damage interviewers' character.

That notwithstanding, indubitably immoral techniques should not be the standard against which stakeholders determine ethical techniques. This criterion is too low. It does not guarantee interviewees' protection, given that investigative interviewing is fraught with epistemic limitations, and governing entities can compel people to interviews. Accordingly, deriving an interviewing method from scientific psychological principles does not necessarily make a technique consent-worthy. The scientific interviewing technique may still obscure an interviewer's inquiry and lead an interviewee to unwittingly disclose information- then the method is arguably psychologically manipulative. I am not suggesting that any interviewing technique that successfully persuades an interviewee to share information is psychologically manipulative. That interpretation is erroneous. The proposal is that methods are psychologically manipulative if they undermine interviewees' agency when convincing them to share information.

An Absolute Standard Based on the Two Principles. Interviewing methods should be held to an absolute standard that actively protects all interviewees, especially vulnerable ones, such as children and people with intellectual disabilities. Broadly speaking, vulnerable interviewees, for various reasons, are highly suggestible and prone to providing information unwittingly (see, e.g., Farrugia \& Gabbert, 2020; Gudjonsson, 2005; O’Mahony et al., 2012). Hence, I propose that the minimum requirement of consent-worthiness should be one that adheres to the inquiry-clarity and disclosure-awareness principles when a vulnerable person undergoes a technique. This standard calls on research psychologists to apply a maximin rule when formulating interviewing methods. The maximin rule is an ethics principle advocating that, typically, the right state of affairs is one structured such that the worst outcome is as acceptable as can be (Rawls, 1971). 
A method should allow the most vulnerable interviewee, within a class of interviewees, maximum agency in determining what to disclose. The standard necessitates research psychologists to be explicit about the possible boundary conditions where a technique fails to be consent-worthy - if such conditions exist. To my knowledge, there is little ongoing discussion about the ethical boundaries of techniques derived from psychological principles. Let us say, for example, one designs a technique to elicit information from suspects. At a minimum, I propose that the method give vulnerable suspects agency to determine what information they want to share. For example, the technique should give the most suggestible suspect, who is prone to falsely confessing, maximum agency to determine what to disclosewithout undermining such ability in any way. This standard is not always attainable. Techniques for vulnerable interviewees may require special considerations. However, the proposed standard tasks developers to indicate the target populations of their methods and not leave that to assumption. For instance, does the method provide agency to neurotypical adults but not adults with intellectual disabilities and children?

It is worth clarifying that this work does not suggest that consent-worthy methods must provide an equal amount of agency to all interviewees within the relevant class. Such a feat will be unproductive and, ultimately, insurmountable due to individual differences. Instead, I am proposing that an interviewing method should generally give interviewees enough (viz., maximum) agency to the extent that when vulnerable interviewees undergo the method, they too will have the agency to decide what they wish to reveal.

An illustration may assist in understanding the proposal. Imagine that the agency a technique provides is a pie. I am not suggesting that an interviewing method should ensure that all interviewees get an equal piece. Equal pieces may still be unacceptable if the pie is too small in the first place. For example, by design, a method may offer little agency to any interviewee. The proposed standard calls for a pie big enough so that even when one gets the smallest slice, 
it will still be acceptable. Put differently, interviewing methods should provide enough agency such that the levels are sufficient even when dealing with vulnerable interviewees. Researchers should be explicit about the boundaries of a method if it cannot achieve this standard. Overall, the proposed standard may allow psychological investigative interviewing techniques to achieve beneficence and nonmaleficence; and respect for rights and dignity (viz., APA, 2002, Principles A and E).

\section{Advancing the Ethics Paradigm: Exploring the Scharff Technique}

The standard proposed here arguably provides fairly straightforward and actionable guidelines for the design of future interviewing techniques. Nonetheless, when it comes to existing methods, it is useful to explore the conditions under which those techniques impact interviewees' agency to promote or undermine consent worthiness. Illustration may help one understand how to engage with the standard when examining a specific technique's ethics. In that light, I will examine the Scharff technique. Researchers developed the Scharff technique by scientifically conceptualizing the interviewing style of Hanns Scharff; a member of the German Luftwaffe, active during World War II $^{2}$. See Granhag et al. (2015) for the first of such conceptualizations (see, also, Oleszkiewicz, 2016).

Choosing the Scharff technique is arbitrary. Every interviewing technique in the published literature should be the subject of an ethics analysis; for example, the variants of the cognitive approach to lie detection (Vrij et al., 2017), the strategic use of evidence framework (Granhag \& Hartwig, 2014), the tactical disclosure of evidence method (Dando \& Bull, 2011), the verifiability approach (Nahari et al., 2014), et cetera. Moreover, this analysis of the Scharff

\footnotetext{
${ }^{2}$ As one can infer, Scharff fought for Nazi Germany, which begs an ethics discussion at a different level of analysis. Suppose an interviewing method is consent-worthy by the standard this article proposes. In that case, does it matter who or what inspired the method? Are there any conditions that ethically justify or should preempt from developing consent-worthy interviewing methods? I am preparing to address these questions in an upcoming article, but see RabbitSnore (2017).
} 
technique is preliminary and not exhaustive; its goal is to encourage open discussions about the ethical boundaries of existing techniques. The objective is not to impugn or be a snare to label the Scharff technique as unethical. The state of the literature will improve through collective effort, not alienation. The present discussion provides an example of a structure and general recommendations. The goal is to get the ball rolling for future examinations of the Scharff technique and all other methods in the published literature.

The current conception of the Scharff technique comprises five components that work in concert to elicit information. These components are best characterized as a way of handling conversations to facilitate the other interlocutor's disclosure - not a checklist of mandatory behaviors to perform in serial order. An interviewer may enact the Scharffian components in any order that suits the goals at hand.

- A friendly interpersonal approach. This component advocates conversing with the interviewee in a non-adversarial manner. The interviewee is to feel relaxed and comfortable, not accused or threatened to comply with demands.

- Not pressing for information. This component charges the interviewer to refrain from asking direct questions or badgering the interviewee with questions. Note that asking direct questions is not synonymous with badgering.

- Creating an impression of omniscience on a topic. This component calls on the interviewer to establish an illusion of possessing substantial information on a topic by presenting truthful information. The presentation could be explicit; for example, the interviewer could talk openly about what they know, like a coherent story. Nevertheless, the goal to create the illusion of omniscience must be subtle, leading the interviewee to perceive they are unlikely to reveal anything new. It is worth noting that exponents of the Scharff technique advocate the use of truthful information, not false evidence ploys. 
- Confirmations and disconfirmations over direct questions. Instead of posing direct questions, the Scharff technique recommends the interviewer to present claims in a manner that invites the interviewee to either confirm or disconfirm. Here is an example fashioned after one provided by Oleszkiewicz (2016). Suppose an interviewer wanted to know if an event is likely to happen at location-x or -y. The interviewer could ask a direct question. Will the event happen at location-x or $-y$ ? Alternatively, one could embed the question in a claim. We know the event is likely to happen at location-x, not $y$. The interviewer is to discern if the interviewee confirms or disconfirms the claim in any way. Drawing on Grice (1975), Luke (2020) notes that the confirmation-disconfirmation tactic may derive from the architecture of conversational norms; interlocutors typically correct each other's mistakes if any arise. Oleszkiewicz et al. (2014) mention that confirmation and disconfirmation alleviate the responsibility on the interviewee to take the initiative of sharing new information. Importantly, the tactic minimizes interviewees' perception of the magnitude of their contribution to the interviewer's knowledge.

- Ignoring new information. This component recommends the interviewer to avoid indicating that an interviewee has disclosed anything significant. The interviewer may achieve this goal in several ways. Examples of those ways include changing topics after the interviewee discloses something significant, downplaying the information, or ignoring it. Luke (2020) theorizes that not acknowledging new information may complement other components like not pressing for information and the confirmation-disconfirmation tactic. This symbiosis may bolster the illusion that the interviewer is indeed omniscient on the relevant topic.

The interested reader may consult Oleszkiewicz (2016) for a more thorough discussion of the Scharff components. 
Overall, the Scharff technique's current conception calls for the interviewer to assure that the interviewee experiences a pleasant interview. Interviewers must strive to view interviewees as persons, not just sources of information (Oleszkiewicz, 2016). Hence, the congeniality should be as authentic as possible, without threats, accusations, emotional manipulation, or accusatory minimization (Luke, 2020; Oleszkiewicz, 2016). Generally speaking, the ethos of the technique is laudable and respects interviewees' dignity.

Based on the extant scientific literature on the Scharff technique, one can infer that proponents intend for interviewers to use it to elicit information from human intelligence (HUMINT) interviewees (e.g., Granhag et al., 2015). This specification is a good start, and the Scharff technique literature offers more, in that regard, than say the cognitive approach to lie detection (see, e.g., Vrij et al., 2017). In fact, this analysis is possible because the Scharff technique literature provides some specifications about the intended target population. Nonetheless, the Scharff body of work is silent regarding which HUMINT interviewees can undergo the technique. For example, is the technique applicable when interviewing children, adolescents, or adults with intellectual disabilities; or is the technique designed for interviews with neurotypical adults only? To be fair, as I mentioned earlier, this issue is pervasive across the investigative interviewing literature; it is not specific to the Schaff technique. Furthermore, it is not clear whether the Scharff technique is recommended for eliciting intelligence in criminal investigations, non-criminal investigations, or both.

To examine the ethics of any interviewing method, researchers must specify its intended applications. It may be worthwhile to approach that task in a manner analogous to the safe and balanced prescribing of medication. The idea is that medical professionals should strive to prescribe medicines appropriate to the condition under treatment with a dosage regimen that minimizes harm to the patient (Aronson, 2006). Thinking along those same lines, it is useful for research psychologists to accompany their recommendations of interviewing 
techniques with dosage regimens that promote judicious usage and flags plus preempts abuse. Next follows an elaboration of how one can offer an appropriate dosage regimen in the investigative interviewing context.

(i) One must first identify the categories of interviewees from which the method aims to elicit information. One must outline why it is permissible to subject that category of interviewees to the recommended technique. There should be empirical evidence or a theoretical discussion describing how the method provides agency that allows the relevant interviewees control over their disclosures.

(ii) It is also equally vital to identify potential categories of interviewees that should not be subjects of the technique. If possible, authors should also specify with theoretical examination or empirical evidence why it is not permissible to subject a category of interviewees to a proposed technique. These specifications allow clear identification of a technique's ethical boundaries. Imagine that the technique seriously undermines the agency of some relevant category of interviewees, but this is left unspecified. Suppose the technique provides neurotypical adults agency to decide their disclosures. However, for whatever reason, when adults with intellectual disabilities undergo the technique, they mistake the interview for a casual conversation. Say it is not immediately apparent to them that what they are saying are disclosures on the record. In that case, the technique fails the inquiry-clarity and disclosureawareness principles. The vulnerable class of interviewees is not aware that the interviewer is asking for information on the record, and they (i.e., interviewees) are choosing to disclose information on that record.

(iii) Finally, authors should aim to anticipate possible misapplications and preempt such possibilities by describing such situations. For example, exponents of the Scharff technique try to prevent misapplication by noting that interviewers should only use truthful informationnot false evidence ploys - to create the omniscience illusion. 
Proponents of an interviewing method are unlikely to always be available to chaperone practicing interviewers when they are potentially misusing the proposed method such that it falls short of consent-worthiness. For that reason, leaving the permitted and protected categories of interviewees unspecified or potential misapplications unaddressed allows dangerous possibilities for abuse. Without specification, one can justify any usage by claiming the technique is recommended in the scientific literature and is therefore ethical. Specifying the permitted and protected categories and flagging possible misuse will challenge researchers to more thoroughly consider the possible risks a seemingly non-coercive technique could be inviting. Exposing those risks will lead researchers to take preemptive action by discontinuing the technique, outlining the boundary conditions, or redesigning it to be fail-safe if possible.

Let us now explore the Scharff technique's consent-worthiness given what is published concerning (a) the category of interviewees from which the method aims to elicit information; (b) the associated risks of being an interviewee in that relevant category; (c) the effects of the Scharff technique on how interviewees think and behave. Based on the extant research, one can assume that the Scharff technique is purposed to elicit information from HUMINT interviewees who are neurotypical adults. A recent meta-analysis examined experiments where neurotypical adults underwent the Scharff technique compared to direct questioning (Luke, 2020). All things being equal, direct questions arguably reveal a questioner's inquiry clearly. A neurotypical adult answering those questions is likely to be aware of what they are choosing to disclose. All things being equal, direct questions satisfy the inquiry-clarity and disclosureawareness principles in serial order. By the standard this article proposes, direct questioning is consent-worthy when interviewing neurotypical adults in an intelligence interview.

The meta-analysis indicated that the Scharff technique generally influences HUMINT interviewees as intended (Luke, 2020). The method leads interviewees to disclose more new 
information. Importantly under Scharffian questioning, interviewees underestimate the amount of new information they disclose relative to what they indeed revealed. The technique also makes interviewees perceive the interviewer as more knowledgeable on the topics of discussion. Finally, the Scharff technique leads interviewees to report greater difficulty in deciphering the interviewer's questioning objectives.

Further research needs to elucidate how the various Scharffian components contribute to the effects just described. However, one can infer that taken together, the components may lead neurotypical adults to unwittingly disclose some information in a HUMINT interview. The use of the word some is not trivial. The meta-analysis (Luke, 2020) suggests that for certain questions, the Scharff technique obscures inquiry-clarity insofar as interviewees report difficulty understanding what information the interviewer is after. Additionally, interviewees disclose more new information and underestimate the amount they actually disclose. That result suggests that the Scharff technique may obscure disclosure-awareness of some items of information.

In the worst-case scenario, during a criminal investigation, for example, when questioning an informant, the technique may reduce the interviewee's agency in deciding whether to reveal or withhold some information items. Suppose those items are not bona fide criminal secrets ${ }^{3}$ but private information outside the scope of the investigation. In that case, the Scharff technique's influence on neurotypical adults' agency is a cause for concern. As discussed previously, epistemic limitations prevent knowing beforehand whether one possesses bona fide criminal secrets. Governing entities have a monopoly on coercion and could compel people to interviews, at least in criminal investigations. Interviewees' recourse from being excessively compelled is to decide their disclosures and object to providing

\footnotetext{
${ }^{3}$ In a liberal democracy, withholding a criminal secret is morally inconsistent with the expectation that governing entities should ensure moral equality when a deviation occurs (Skerker, 2010).
} 
information if they wish (Skerker, 2010). Proponents must address this potential ethical boundary of the Scharff technique when it comes to HUMINT interviewees in criminal investigations.

Similar concerns to the one just described arise when considering Scharffian influence on HUMINT interviewees in non-criminal investigations. An example of a non-criminal investigation is a clandestine interview to collect information aimed at directing foreign policy. As discussed earlier, the risks in those interviews are highly unpredictable. Typically, there are hardly any codified rules (e.g., constitutions) stipulating the potential outcomes of disclosure for the interviewee. Those outcomes could be innocuous or pernicious, but one cannot be entirely sure before disclosing the information. The Scharff technique reduces agency to decide some disclosures. Hence, the technique may prevent an interviewee from withholding what they have not formed a clear intention to share. For those items of information, the Scharff technique falls short of the inquiry-clarity and disclosure-awareness principles. There is a need to examine the flagged potential ethical boundary that could arise in non-criminal investigations.

As noted previously, the present analysis is preliminary. The current conception of the Scharff technique may change. There is also the need for more research to examine what precisely the Scharffian components cause interviewees to disclose. The meta-analysis indicates that the Scharff technique, compared to direct questions, leads interviewees to disclose a higher amount of information (Luke, 2020). Nonetheless, it is unclear what information people share in response to the technique. The underlying mechanisms of the technique remain largely unknown. Thus, it is uncertain which components exert the elicitation influences and why interviewees reveal the information they do. Maybe, Scharffian tactics generally elicit information that interviewees must legitimately reveal, for example, criminal secrets. Further research may also indicate that the technique leads interviewees to unwittingly 
share information irrespective of the information's characteristics. These questions remain unanswered. Answering the pending research questions will assist in conducting further ethical analysis to comprehensively determine the Scharff technique's consent-worthiness.

\section{Concluding Remarks}

This article has proposed an ethics standard that may guide the formulation of psychological interviewing methods. That is, interviewing techniques should provide interviewees, particularly vulnerable ones, enough agency to freely determine what to disclose. This standard is feasible in governances, pertinently, liberal democracies, that arguably respect the natural rights of the governed and persons in general. Applying the principles to develop interviewing methods in immoral contexts like totalitarian regimes that do not aim to respect the rights of the governed would be unethical by default.

In their publications, researchers should explicitly indicate the boundary conditions of a technique if it cannot achieve the proposed standard. Journal editors and reviewers should request such discussions. It is worth noting that this proposal does not call for researchers to cease exploring how people think and behave in investigative interviews. As such, I do not intend for this work to stifle the exploration of interviewing methods. It is vital to understand the enterprise of interviewing to facilitate navigating it ethically. The suggested standard tasks research psychologists to be circumspect about recommending psychological techniques without (fully) addressing the ethical boundaries of those methods in their publications.

The field must adopt fairly unambiguous metrics to examine the ethics of interviewing methods authors aim to publish. We must relinquish the comforting fiction that techniques devoid of blatant physical or psychological coercion are automatically ethical without actively investigating those methods. Indubitably immoral techniques that take advantage of suggestible interviewees to elicit false confessions or collect information nefariously should not be the standard against which research psychologists determine ethical techniques - this 
criterion is too low. Psychology research needs further theoretical and empirical work that proactively ensures that current and future publications of interviewing methods protect various interviewees against potential manipulation.

In addition to thinking about how a method may facilitate disclosure, research psychologists must also be cognizant of the potential misuse or misapplication of the techniques they publish. This article's contribution is that it specifies criteria by which to examine the ethical nature of interviewing methods researchers publish, reducing ambiguity about what constitutes psychological manipulation. Investigative interviewing entails considerable moral risks. Stakeholders must take steps to avoid ambiguity about what constitutes consent-worthy methods of eliciting information from interviewees. 


\section{References}

Alison, L., \& Alison, E. (2017). Revenge versus rapport: Interrogation, terrorism, and torture. American Psychologist, 72(3), 266-277. https://doi.org/10.1037/amp0000064

APA (2002). Ethical principles of psychologists and code of conduct. American Psychologist, 57(12), 1060-1073. http://dx.doi.org.ezproxy.ub.gu.se/10.1037/0003-066X.57.12.1060

Aronson, J. K. (2006). Balanced prescribing. British Journal of Clinical Pharmacology, 62(6), 629-632. https://doi.org/10.1111/j.1365-2125.2006.02825.x

Bandes, S. A. (2009). Protecting the Innocent as the Primary value of the Criminal Justice System Book Review. Ohio State Journal of Criminal Law, 7(1), 413-438.

Bayles, M. E. (2012). Procedural Justice: Allocating to Individuals. Springer Science \& Business Media.

Behnke S: APA's Ethical Principles of Psychologists and Code of Conduct: An ethics code for all psychologists...? Monitor on Psychology 2006, 37(8):66.

Bok, S. (1989). Secrets: On the ethics of concealment and revelation. Vintage.

Burkett, R. (2013). An Alternative Framework for Agent Recruitment: From MICE to RASCLS. Studies in Intelligence, 57(1), 12.

Carter, D. L. (1990) Law enforcement intelligence operations: An overview of concepts, issues and terms. Washington, DC: National Institute of Justice.

Cassell, P. (2017). Can We Protect the Innocent Without Freeing the Guilty? Thoughts on Innocence Reforms that Avoid Harmful Tradeoffs. In D. Medwed (Ed.), Thoughts on Innocence Reforms that Avoid Harmful Tradeoffs. Wrongful Convictions and the DNA Revolution: Twenty-Five Years of Freeing the Innocent (p. 25). Cambridge University Press.

Clarke, C. \& Milne, B. (2001). National Evaluation of Investigative Interviewing PEACE Course. Home Office, London. Retrieved from https://www.researchgate.net/profile/Colin_Clarke3/publication/263127370_National_Evalua 
tion_of_the_PEACE_Investigative_Interviewing_Course/links/53da3b620cf2e38c63366507. pdf

Cohen, S. (2005). Post-Moral Torture: From Guantanamo To Abu Ghraib. Index on Censorship, 34(1), 24-30. https://doi.org/10.1080/03064220512331339427

College of policing. (2019). Investigative interviewing. Retrieved June 26, 2019, from https://www.app.college.police.uk/app-content/investigations/investigativeinterviewing/\#peace-framework

Dando, C. J., \& Bull, R. (2011). Maximising Opportunities to Detect Verbal Deception: Training Police Officers to Interview Tactically. Journal of Investigative Psychology and Offender Profiling, 8(2), 189-202. https://doi.org/10.1002/jip.145

Fallon, M. (2014). Collaboration Between Practice and Science Will Enhance Interrogations. Applied Cognitive Psychology, 28(6), 949-950. https://doi.org/10.1002/acp.3091

Farrugia, L., \& Gabbert, F. (2020). Vulnerable suspects in police interviews: Exploring current practice in England and Wales. Journal of Investigative Psychology and Offender Profiling, 17(1), 17-30. https://doi.org/10.1002/jip.1537

Frith, C. D. (2014). Action, agency and responsibility. Neuropsychologia, 55, 137-142. https://doi.org/10.1016/j.neuropsychologia.2013.09.007

Glasius, M. (2006). The International Criminal Court: A Global Civil Society Achievement. Routledge. https://doi.org/10.4324/9780203414514

Granhag, P. A., Montecinos, S. C., \& Oleszkiewicz, S. (2015). Eliciting intelligence from sources: The first scientific test of the Scharff technique. Legal and Criminological Psychology, 20(1), 96-113. https://doi.org/10.1111/lcrp.12015

Granhag, P. A., \& Hartwig, M. (2014). The Strategic Use of Evidence Technique: A Conceptual Overview. In Detecting Deception (pp. 231-251). John Wiley \& Sons, Ltd. https://doi.org/10.1002/9781118510001.ch10 
Grice, H. P. (1975). Logic and conversation. In P. Cole \& J. Morgan (Eds.),

Gudjonsson, G. (2005). Disputed Confessions and Miscarriages of Justice in Britain: Expert

Psychological and Psychiatric Evidence in the Court of Appeal. Manitoba Law Journal, $31(3), 489-522$.

Haggard, P., \& Tsakiris, M. (2009). The Experience of Agency: Feelings, Judgments, and

Responsibility. Current Directions in Psychological Science.

https://journals.sagepub.com/doi/10.1111/j.1467-8721.2009.01644.X

Hartwig, M., Luke, T. J., \& Skerker, M. (2016). Ethical perspectives on interrogation. In J. Jacobs \& J. Jackson (Eds.), The Routledge Handbook of Criminal Justice Ethics, (pp. 326-344). New York, NY: Routledge.

Hartwig, M., Meissner, C. A., \& Semel, M. D. (2014). Human Intelligence Interviewing and Interrogation: Assessing the Challenges of Developing an Ethical, Evidence-based Approach. In R. Bull (Ed.), Investigative Interviewing (pp. 209-228). Springer.

https://doi.org/10.1007/978-1-4614-9642-7 11

Inbau, F. E., Reid, J. E., Buckley, J. P., \& Jayne, B. C. (2001). Criminal interrogation and confessions (4th ed). Sudbury, MA: Jones and Bartlett.

Kassin, S. M. (2017a). False confessions. WIREs Cognitive Science, 8(6), e1439. https://doi.org/10.1002/wcs.1439

Kassin, S. M. (2017b). False confessions: How can psychology so basic be so counterintuitive? American Psychologist, 72(9), 951-964. http://dx.doi.org.ezproxy.ub.gu.se/10.1037/amp0000195

Kassin, S. M., \& Kiechel, K. L. (1996). The Social Psychology of False Confessions: Compliance, Internalization, and Confabulation. Psychological Science, 7(3), 125-128.

https://doi.org/10.1111/j.1467-9280.1996.tb00344.x 
Luke, T. J. (2020). A meta-analytic review of experimental tests of the interrogation technique of Hanns Joachim Scharff. Applied Cognitive Psychology, acp.3771. https://doi.org/10.1002/acp.3771

Meissner, C. A. (2021). "What works?” Systematic reviews and meta-analyses of the investigative interviewing research literature. Applied Cognitive Psychology, 35(2), 322-328. https://doi.org/10.1002/acp.3808

Meissner, C. A., Kelly, C. E., \& Woestehoff, S. A. (2015). Improving the Effectiveness of Suspect Interrogations. Annual Review of Law and Social Science, 11(1), 211-233. https://doi.org/10.1146/annurev-lawsocsci-120814-121657

Moore, J. W. (2016). What Is the Sense of Agency and Why Does it Matter? Frontiers in Psychology, 7. https://doi.org/10.3389/fpsyg.2016.01272

Morrison, W. (2013). What is crime? Contrasting definitions and perspectives. In C. Hale, K. Hayward, A. Wahidin, \& E. Wincup (Eds.), Criminology. OUP Oxford.

Mukand, S. W., \& Rodrik, D. (2020). The Political Economy of Liberal Democracy. The Economic Journal, 130(627), 765-792. https://doi.org/10.1093/ej/ueaa004

Nahari, G., Vrij, A., \& Fisher, R. P. (2014). Exploiting liars' verbal strategies by examining the verifiability of details. Legal and Criminological Psychology, 19(2), 227-239. https://doi.org/10.1111/j.2044-8333.2012.02069.x

Newton, T. (1998). The Place of Ethics in Investigative Interviewing by Police Officers. The Howard Journal of Criminal Justice, 37(1), 52-69. https://doi.org/10.1111/1468-2311.00077 Nozick, R. (1974). Anarchy, state, and utopia (Vol. 5038). New York: Basic Books. O’Mahony, B. M., Milne, B., \& Grant, T. (2012). To Challenge, or not to Challenge? Best Practice when Interviewing Vulnerable Suspects. Policing: A Journal of Policy and Practice, 6(3), 301-313. https://doi.org/10.1093/police/pas027 
Oleszkiewicz, S. (2016). Eliciting human intelligence a conceptualization and empirical testing of the Scharff-technique [Department of Psychology, University of Gothenburg]. http://hdl.handle.net/2077/41567

Oleszkiewicz, S., Granhag, P. A., \& Kleinman, S. M. (2014). On Eliciting Intelligence from Human Sources: Contextualizing the Scharff-Technique. Applied Cognitive Psychology, 28(6), 898-907. https://doi.org/10.1002/acp.3073

Pieck, M. (1960). Witness Privilege against Self-Incrimination in the Civil Law. Villanova Law Review, 5, 33 .

Porter, S., Rose, K., \& Dilley, T. (2016). Enhanced interrogations: The expanding roles of psychology in police investigations in Canada. Canadian Psychology/Psychologie Canadienne, 57(1), 35-43. https://doi.org/10.1037/cap0000042

RabbitSnore (2017). The moral backdrop of interrogations. Rabbit Tracks. https://www.rabbitsnore.com/2017/11/the-moral-backdrop-of-interrogations.html

Rachlew, A. (2017, March 14). From interrogating to interviewing suspects of terror: Towards a new mindset. Penal Reform International. https://www.penalreform.org/blog/interrogatinginterviewing-suspects-terror-towards-new-mindset/

Ransom, H. H. (2013). The Intelligence Establishment. In The Intelligence Establishment. Harvard University Press. https://hup.degruyter.com/view/title/323605

Rawls, J (1971). A Theory of Justice. Harvard University Press; Cambridge.

Read, D., Craik, F. I. M., \& Link to external site, this link will open in a new window. (1995). Earwitness identification: Some influences on voice recognition. Journal of Experimental Psychology: Applied, 1(1), 6-18. http://dx.doi.org.ezproxy.ub.gu.se/10.1037/1076$\underline{898 X .1 .1 .6}$ 
Seidmann, D. J., \& Stein, A. (2000). The Right to Silence Helps the Innocent: A Game-Theoretic Analysis of the Fifth Amendment Privilege. Harvard Law Review, 114(2), 430-510. JSTOR. https://doi.org/10.2307/1342573

Skerker, M. (2010). An Ethics of Interrogation. University of Chicago Press.

Snook, B., Barron, T., Fallon, L., Kassin, S. M., Kleinman, S., Leo, R. A., Meissner, C. A., Morello, L., Nirider, L. H., Redlich, A. D., \& Trainum, J. L. (2020). Urgent issues and prospects in reforming interrogation practices in the United States and Canada. Legal and Criminological Psychology, 26(1), 1-24. https://doi.org/10.1111/lcrp.12178

Spalek, B. (2016). Crime Victims: Theory, Policy and Practice. Macmillan International Higher Education.

Sukumar, D., Wade, K. A., \& Hodgson, J. S. (2016). Strategic disclosure of evidence:

Perspectives from psychology and law. Psychology, Public Policy, and Law, 22(3), 306-313. https://doi.org/10.1037/law0000092

Syntax and semantics (Vol. 3, pp. 41-58). Academic Press.

Tadros, V. (2011). Consent to Harm. Current Legal Problems, 64(1), 23-49. https://doi.org/10.1093/clp/cur004

Tierney, J. (2009). Criminology: Theory and Context. Pearson Education.

Vrij, A. (2018). Deception and truth detection when analyzing nonverbal and verbal cues. Applied Cognitive Psychology. https://doi.org/10.1002/acp.3457

Vrij, A., \& Granhag, P. A. (2014). Eliciting Information and Detecting Lies in Intelligence Interviewing: An Overview Of Recent Research. Applied Cognitive Psychology, 28(6), 936944. https://doi.org/10.1002/acp.3071

Vrij, A., Fisher, R. P., \& Blank, H. (2017). A cognitive approach to lie detection: A meta-analysis. Legal and Criminological Psychology, 22(1), 1-21. https://doi.org/10.1111/lcrp.12088 
Vrij, A., Meissner, C. A., Fisher, R. P., Kassin, S. M., Morgan, C. A., \& Kleinman, S. M. (2017). Psychological Perspectives on Interrogation. Perspectives on Psychological Science, 12(6), 927-955. https://doi.org/10.1177/1745691617706515

Wells, G. L., \& Olson, E. A. (2003). Eyewitness testimony. Annual Review of Psychology; Palo Alto, 54, 277-295.

http://dx.doi.org.ezproxy.ub.gu.se/10.1146/annurev.psych.54.101601.145028

Williamson, T. M. (1993). From interrogation to investigative interviewing; strategic trends in police questioning. Journal of Community \& Applied Social Psychology, 3(2), 89-99. https://doi.org/10.1002/casp.2450030203 